\title{
Low-temperature oxidation of carbon monoxide and methane over alumina and ceria supported platinum catalysts
}

\author{
Per-Anders Carlsson * and Magnus Skoglundh \\ Department of Chemical and Biological Engineering and Competence Centre for Catalysis, Chalmers University of Technology, SE-412 96 \\ Göteborg, Sweden
}

\begin{abstract}
The ignition- and extinction processes for total oxidation of $\mathrm{CO}, \mathrm{CH}_{4}$ and $\mathrm{CO}+\mathrm{CH}_{4}$ mixture in oxygen excess over $\mathrm{Pt} / \mathrm{Al}_{2} \mathrm{O}_{3}$ and $\mathrm{Pt} / \mathrm{CeO}_{2}$ catalysts with the platinum phase distributed either homogeneously or heterogeneously (i.e., locally high platinum concentration) in the support have been studied by temperature programmed oxidation experiments. Following the preparation methods by Arnby et al. [J. Catal. 221 (2004) 252-261], the samples have the same Pt load and dispersion. Generally the catalytic activity follows the order: $\mathrm{Pt} / \mathrm{CeO}_{2}$ (heterogeneous) $>\mathrm{Pt} / \mathrm{CeO}_{2}$ (homogeneous) $>\mathrm{Pt} / \mathrm{Al}_{2} \mathrm{O}_{3}$ (heterogeneous) $>\mathrm{Pt} / \mathrm{Al}_{2} \mathrm{O}_{3}$ (homogeneous) as indicated by lower ignition- and/or extinction temperatures. For $\mathrm{Pt} / \mathrm{Al}_{2} \mathrm{O}_{3}$, the addition of $\mathrm{NO}_{2}$ to the reactant stream increases the rate of oxidation of $\mathrm{CO}$ in the pre-ignition regime although the light-off temperature $\mathrm{T}_{50}$ is shifted towards higher temperatures (except for low $\mathrm{CO}$ concentrations). In the case of the $\mathrm{Pt} / \mathrm{CeO}_{2}$, the $\mathrm{CO}$ conversion generally decreases. For $\mathrm{CH}_{4}$ oxidation in the presence of $\mathrm{NO}_{2}$, the conversion increases for $\mathrm{Pt} / \mathrm{Al}_{2} \mathrm{O}_{3}$ and decreases for $\mathrm{Pt} / \mathrm{CeO}$. The addition of $\mathrm{CO}_{2}$ in the reactant stream has minor influence on $\mathrm{CO}$ oxidation over $\mathrm{Pt} / \mathrm{Al}_{2} \mathrm{O}_{3}$ while for $\mathrm{Pt} / \mathrm{CeO}_{2}, \mathrm{~T}_{50}$ is shifted towards higher temperatures. For the simultaneous oxidation of $\mathrm{CO}$ and $\mathrm{CH}_{4}$, a reverse hysteresis for methane oxidation is observed, i.e., the extinction process occurs at higher temperature than the corresponding ignition process. The improved activity for CO oxidation over samples with heterogeneous Pt distribution is likely due to less tendency towards CO self-poisoning through the development of steeper concentration gradients in the Pt containing regions in the porous support material.The significant increase of activity for both reactions over ceria-supported $\mathrm{Pt}$ is here assigned to highly active sites at the platinum-ceria boundary but also, to some extent, the oxygen storage- and release function and dynamics of the transport of oxygen in the $\mathrm{Pt} / \mathrm{CeO}{ }_{2}$ system.
\end{abstract}

Key words: catalytic ignition; catalytic extinction; metal-support interactions; diffusion

\section{Introduction}

The catalytic oxidation of carbon monoxide (CO) and hydrocarbons $(\mathrm{HC})$ are key reactions in many industrial chemical processes as well as pollution control for automotives and industrial processes [1]. Within the automotive sector, $\mathrm{CO}$ and $\mathrm{HC}$ present in the engine exhausts are often efficiently converted to carbon dioxide and water by complete oxidation over monolith catalysts, typically, noble metals supported on metal oxides, mounted in the exhaust system $[2,3]$. Occasionally, however, obstacles associated with blocking of catalytic sites by the reactants at low temperatures, so-called self-poisoning, results in poor catalytic performance leading to, for example, high cold-start

\footnotetext{
* Corresponding author.

Email address: per-anders.carlsson@chalmers.se (Per-Anders Carlsson).
}

emissions [2-4]. In this connection self-poisoning has often been considered a transient ignition problem mainly solved by strategies for rapid warm-up of the catalysts [5]. This view, however, is about to change. The present development towards more efficient engine combustion concepts, e.g., homogeneous charge compression ignition (HCCI) combustion, leads to low-temperature exhausts $\left(\sim 150^{\circ} \mathrm{C}\right.$ for significant periods) with considerable levels of $\mathrm{CO}$ and $\mathrm{HC}$ including methane $\left(\mathrm{CH}_{4}\right)[6,7]$. Thus the need for catalysts that are active for continuous operation at low temperatures is increasing.

It is well known that the oxidation of $\mathrm{CO}$ on platinum at low pressures exhibits two distinct kinetic regimes, one $\mathrm{CO}$ self-poisoned region with low activity and one regime where the surface is predominantly covered with chemisorbed oxygen resulting in high activity [8,9]. Depending on reaction conditions, i.e., temperature and reactant concentrations, the two regimes may overlap forming a region with bistable 
kinetics. Thus, in the bistable region, the kinetics is not only dependent on the actual reaction conditions but also the reaction history [9-11]. The same phenomena may occur also for supported Pt crystallites at atmospheric pressures [12-15] although the kinetics may be further complicated by, e.g., strong metal-support interactions (SMSI) [16,17], adsorbate diffusion over metal-support boundaries $[18,19]$ and oxide formation [20,21].

Catalytic oxidation of saturated hydrocarbons, and especially methane, is considerably more difficult than oxidation of other hydrocarbons or oxygenates with the same carbon chain lengths. In the case of $\mathrm{CH}_{4}$ this is reflected by the relatively high temperatures required for the catalytic oxidation to proceed. The rate-limiting step is considered to be the abstraction of the first hydrogen [22], which in terms of catalysis means the dissociative adsorption of $\mathrm{CH}_{4}$. On $\mathrm{Pt}$, the sticking coefficient is relatively low compared to that of higher alkanes [23] hence the overall methane oxidation rate is also relatively low. In contrast to $\mathrm{CO}$ oxidation, oxidation of saturated hydrocarbons and specifically methane over platinum catalysts may suffer from oxygen poisoning [14,24,26-29] leading to low reaction rates [30,31]. Improving the low-temperature activity for simultaneous oxidation of $\mathrm{CO}$ and $\mathrm{CH}_{4}$ over supported $\mathrm{Pt}$ is thus a dilemma. In the case of $\mathrm{CO}$ oxidation the key issue is to facilitate oxygen supply to the Pt crystallites, while for oxidation of $\mathrm{CH}_{4}$ an efficient oxygen supply may lead to oxygen poisoning.

One strategy to promote oxidation of $\mathrm{CO} / \mathrm{CH}_{4}$ is to deliberately facilitate the transport of oxygen to/from $\mathrm{Pt}$ by appropriate choice of the support material. For example in three-way catalysis, ceria provides oxygen, which is stored under oxidizing conditions, for the conversion of $\mathrm{CO}$ and $\mathrm{HC}$ under reducing conditions [32-34]. Ceria is also considered to promote the water-gas-shift reaction [35] and promote noble metal dispersion [36,37]. For Pt catalysts it has been shown that using ceria $\left(\mathrm{CeO}_{2}\right)$, instead of silica $\left(\mathrm{SiO}_{2}\right)$ or alumina $\left(\mathrm{Al}_{2} \mathrm{O}_{3}\right)$, as supporting material significantly can improve the activity for $\mathrm{CO}$ oxidation $[38,39]$. Recent results [40] and in particular this study, show that the use of ceria can improve also the activity for oxidation of $\mathrm{CH}_{4}$. In another strategy to improve $\mathrm{CO}$ oxidation over $\mathrm{Pt} / \mathrm{Al}_{2} \mathrm{O}_{3}$ monolith catalysts at low-temperatures, Arnby et al. $[26,42]$ demonstrated an interesting concept based on heterogeneous distribution (local high concentration) of $\mathrm{Pt}$ in the alumina support. For such catalysts primarily the extinction of $\mathrm{CO}$ oxidation shifted towards lower temperatures thus widening the ignition-extinction hysteresis as compared to the corresponding conventional catalysts with homogeneous $\mathrm{Pt}$ distribution in the support material. The mechanisms behind these observations were thoroughly discussed in terms of difference in mass transfer resulting in less CO self-poisoning, difference in heat transfer leading to locally hot regions and a structure sensitive reaction dependent on the local $\mathrm{Pt}$ load. In principle, assuming that heat transfer is the main cause, heterogeneous $\mathrm{Pt}$ distribution may facilitate also $\mathrm{CH}_{4}$ oxidation as, generally, reaction rates increase (exponentially) with temperature.
The present study concerns the total oxidation of $\mathrm{CO}$, $\mathrm{CH}_{4}$ and $\mathrm{CO}+\mathrm{CH}_{4}$ mixture with oxygen over $\mathrm{Pt} / \mathrm{Al}_{2} \mathrm{O}_{3}$ and $\mathrm{Pt} / \mathrm{CeO}_{2}$ monolith catalysts. Specifically, the influence of distribution of the active phase in the catalyst layer and choice of support material on the ignition- and extinction processes are studied by temperature programmed oxidation experiments. The effects of $\mathrm{NO}_{2}$ and $\mathrm{CO}_{2}$ on these processes are also studied.

\section{Experimental section}

\subsection{Catalyst preparation and characterisation}

Four different types of supported Pt catalysts were prepared and characterised in terms of apparent total Pt surface area. Following the preparation methods by Arnby et al. [42], catalysts with either homogeneous or heterogeneous distribution of the $\mathrm{Pt}$ in the support material were prepared using either alumina or ceria as support material. The main steps in the preparation methods are summarised below.

\subsection{1. $\mathrm{Pt} / \mathrm{Al}_{2} \mathrm{O}_{3}$ and $\mathrm{Pt} / \mathrm{CeO} \mathrm{O}_{2}$ powder catalysts}

The alumina supported Pt samples were prepared by impregnating alumina (Puralox S Ba 200, particle diameter $45 \mu \mathrm{m}$, Sasol Germany $\mathrm{GmbH}$ ) that has been precalcined in air at $600^{\circ} \mathrm{C}$ for $2 \mathrm{~h}$ with a halogen-free platinum precursor. Alumina was dispersed in distilled water, and an aqueous solution of $\mathrm{Pt}\left(\mathrm{NO}_{3}\right)_{2}$ (W. C. Heraeus GmbH \& Co. KG) was added dropwise to the alumina slurry under continuous stirring. The slurry was thereafter instantly frozen with liquid nitrogen and freeze-dried. The resulting powder was calcined in air at $600^{\circ} \mathrm{C}$ for $1.5 \mathrm{~h}$. The corresponding ceria supported $\mathrm{Pt}$ samples were prepared analogously using ceria (99.5 HA514, particle size 10-20 nm, Rhône-Poulenc) instead. Two different Pt loadings, i.e., 1 and 10 wt.-\%, were prepared for each support material.

\subsubsection{Monolith catalysts with homogeneous and heterogeneous Pt distribution}

Monolith samples (length $=15 \mathrm{~mm}, \varnothing=12 \mathrm{~mm}$ ) were cut out from a commercial honeycomb structure with $400 \mathrm{cpsi}$. The $\mathrm{Pt} / \mathrm{Al}_{2} \mathrm{O}_{3}$ monolith catalyst with homogeneous Pt distribution was prepared by immersing the monolith body into a well stirred washcoat slurry consisting of the $1 \mathrm{wt}$.$\% \mathrm{Pt} / \mathrm{Al}_{2} \mathrm{O}_{3}$ powder ( $75 \%$ of the total support content), boehmite sol (Disperal sol P2, particle size $25 \mathrm{~nm}$, Condea) and distilled water. The sample was dried in air at $100^{\circ} \mathrm{C}$ for $2 \mathrm{~min}$ and calcined, also in air, at $600^{\circ} \mathrm{C}$ for $3 \mathrm{~min}$. This procedure was repeated until $200 \mathrm{mg}$ of washcoat was applied on the monolith. This correspond to 0.12 $\mathrm{g}$ coating per $\mathrm{cm}^{3}$ monolith catalyst. The sample was then finally calcined in air at $600^{\circ} \mathrm{C}$ for $2 \mathrm{~h}$. The $\mathrm{Pt} / \mathrm{Al}_{2} \mathrm{O}_{3}$ catalyst with heterogeneous $\mathrm{Pt}$ distribution was prepared analogously using instead a washcoat slurry consisting of the 10 wt.- $\% \mathrm{Pt} / \mathrm{Al}_{2} \mathrm{O}_{3}$ powder $(7.5 \%$ of the total support 
Table 1

Summary of reaction conditions. The heating/cooling ramp rate was $5^{\circ} \mathrm{C} / \mathrm{min}$ and the temperature was kept constant for $10 \mathrm{~min}$ at the highest and lowest temperatures.

\begin{tabular}{c|c}
\hline Thermal sequence $\left[{ }^{\circ} \mathrm{C}\right]$ & Feed gas composition \\
\hline $350 \rightarrow 50 \rightarrow 350$ & $0.1 \% \mathrm{CO}+9 \% \mathrm{O}_{2}$ \\
$"$ & $1 \% \mathrm{CO}+9 \% \mathrm{O}_{2}$ \\
$"$ & $0.1 \% \mathrm{CO}+9 \% \mathrm{O}_{2}+0.03 \% \mathrm{NO}_{2}$ \\
$"$ & $1 \% \mathrm{CO}+9 \% \mathrm{O}_{2}+0.03 \% \mathrm{NO}_{2}$ \\
$"$ & $0.1 \% \mathrm{CO}+9 \% \mathrm{O}_{2}+5 \% \mathrm{CO}_{2}$ \\
$550 \rightarrow 50 \rightarrow 550$ & $1 \% \mathrm{CO}+9 \% \mathrm{O}_{2}+5 \% \mathrm{CO}_{2}$ \\
& $0.05 \% \mathrm{CH}+9 \% \mathrm{O}_{2}$ \\
& $0.05 \% \mathrm{CH}+9 \% \mathrm{O}_{2}+0.03 \% \mathrm{NO}_{2}$ \\
& $1 \% \mathrm{CO}+0.05 \% \mathrm{CH}_{4}+9 \% \mathrm{O}_{2}$ \\
\hline
\end{tabular}

content), alumina, boehmite sol and distilled water. The $\mathrm{Pt} / \mathrm{CeO}_{2}$ monolith catalysts were prepared accordingly using in the case of homogeneous $\mathrm{Pt}$ distribution a washcoat slurry consisting of 1 wt.- $\% \mathrm{Pt} / \mathrm{CeO}_{2}$ powder $(75 \%$ of the total support content), ceria sol $\left(\mathrm{CeO}_{2}\right.$ (ACT), particle size 10-20 nm, Nyacol Nano Technologies, Inc.) and distilled water, and in the case of heterogeneous $\mathrm{Pt}$ distribution a slurry of the 10 wt.- $\% \mathrm{Pt} / \mathrm{CeO}_{2}$ powder $(7.5 \%$ of the total support content), ceria, ceria sol and distilled water. The apparent Pt surface area was characterised by the amount of adsorbed $\mathrm{CO}$ which was determined by temperature programmed CO desorption experiments. The adsorbed amount of $\mathrm{CO}$ for the respective catalyst was 1.35 (homogeneous $\mathrm{Pt} / \mathrm{Al}_{2} \mathrm{O}_{3}$ ), 1.30 (heterogeneous $\mathrm{Pt} / \mathrm{Al}_{2} \mathrm{O}_{3}, 0.5$ (homogeneous $\mathrm{Pt} / \mathrm{CeO}_{2}$ ) and 1.48 (heterogeneous $\mathrm{Pt} / \mathrm{CeO}_{2}$ ) $\mu \mathrm{mol}$ per monolith catalyst. For the alumina samples, the obtained values are close while for the ceria samples the values are diverging especially for the homogeneous $\mathrm{Pt} / \mathrm{CeO}_{2}$ sample. In contrast to alumina-based catalysts, the determination of noble metal dispersion on ceria-based samples is not straightforward due to the inherent properties of the platinum-ceria system, e.g., adsorption/desoprtion phenomena on the ceria phase, redox behaviour and spillover mechanisms [43]. Thus we consider the present values obtained for the $\mathrm{Pt} / \mathrm{CeO}_{2}$ catalysts as indications rather than precise measures of the apparent $\mathrm{Pt}$ surface area.

\subsection{Catalyst activity measurements}

\subsubsection{Continuous gas flow-reactor design}

The CO oxidation experiments were carried out using a continuous gas-flow reactor as described elsewhere [44]. Briefly, it consists of a horizontal quartz tube $(\mathrm{L}=600 \mathrm{~mm}$, $\varnothing=15 \mathrm{~mm}$ ) surrounded by a metal coil for resistive heating. The quartz tube and heating coil were carefully insulated. Two thermocouples (Reckman type K) were used to measure, respectively, the inlet gas temperature $11 \mathrm{~mm}$ upstream of the front of the sample and the catalyst temperature in the center of the monolith body. The inde- pendent inlet gas temperature was used for temperature control via a standard PID regulator (Eurotherm). Gases were introduced to the reactor via individual mass flow controllers (Bronkhorst Hi-Tech). The product stream was analysed on-line with respect to $\mathrm{CO}$ and $\mathrm{CO}_{2}$ concentrations using non-dispersive infrared analysers (UNOR $6 \mathrm{~N}$, Maihak). Analogous to the $\mathrm{CO}$ oxidation experiments, the methane oxidation experiments were carried out using a similar continuous gas-flow reactor set-up [27]. In this case, however, the product stream was continuously analysed by mass spectrometry (Balzers Quadstar 422) following the $\mathrm{m} / \mathrm{z}$ ratios $2\left(\mathrm{H}_{2}\right), 15\left(\mathrm{CH}_{4}\right), 18\left(\mathrm{H}_{2} \mathrm{O}\right), 28(\mathrm{CO}), 32\left(\mathrm{O}_{2}\right)$ $40(\mathrm{Ar})$ and $44\left(\mathrm{CO}_{2}\right)$.

\subsubsection{Temperature programmed oxidation experiments}

The influence of the $\mathrm{Pt}$ distribution and the support material on the ignition- and extinction processes for oxidation of $\mathrm{CO}, \mathrm{CH}_{4}$ and $\mathrm{CO}+\mathrm{CH}_{4}$ mixture, respectively, were studied by temperature programmed oxidation (TPO) experiments using heating/cooling ramps of $5^{\circ} \mathrm{C} / \mathrm{min}$ and constant feed gas composition. This heating/cooling ramp rate allowed for two data acquisitions per ${ }^{\circ} \mathrm{C}$. Special attention was paid to the influence of $\mathrm{NO}_{2}$ on the ignition- and extinction processes for $\mathrm{CO}$ and $\mathrm{CH}_{4}$ oxidation. Also the influence of $\mathrm{CO}_{2}$ on the $\mathrm{CO}$ oxidation was studied. Generally the experiments were carried out such that the extinction process was first studied followed by the ignition process. For the $\mathrm{CO}$ oxidation experiments the total gas flow was $1500 \mathrm{ml} / \mathrm{min}$ (NTP) corresponding to a space velocity of about $75000 \mathrm{~h}^{-1}\left(\mathrm{~N}_{2}\right.$ as balance). In all experiments with $\mathrm{CH}_{4}$ and $\mathrm{CO}+\mathrm{CH}_{4}$ mixture, the total gas flow was $400 \mathrm{~mL}$ (NTP)/min corresponding to a space velocity of $20000 \mathrm{~h}^{-1}$ (Ar as balance). For all experiments, the thermal sequence and feed gas composition, are summarised in Table 1.

\section{Results and discussion}

\subsection{Oxidation of $C O$}

Figure 1 shows the results from TPO of 0.1 and $1 \% \mathrm{CO}$ over homogeneous (top panel) and heterogeneous (bottom panel) $\mathrm{Pt} / \mathrm{Al}_{2} \mathrm{O}_{3}$ during heating-cooling ramps. In Table 2 the temperatures corresponding to $50 \%$ reactant conversion for all ignition- and extinction experiments are summarised. In the ignition experiments, the $\mathrm{CO}$ conversion follows a typical light-off process for oxidation of $\mathrm{CO}$ over platinum, which occurs through three main phases. The first phase describes the situation at low $\mathrm{CO}$ conversions. In this phase, the competitive adsorption of $\mathrm{CO}$ and $\mathrm{O}_{2}$ favors $\mathrm{CO}$ adsorption to such an extent that the reaction is CO self-poisoned [13]. Thus the CO conversion is low and the reaction is kinetically controlled. Next phase covers intermediate conversions. Here the reaction rate becomes controlled by internal diffusion in the porous support material of the catalyst, thus turning from the first to the second phase means a shift in rate-determining step (RDS). 
According to Weisz and Prater [45], internal diffusion will affect a first-order reaction for values of the Weisz modulus $(\Phi)$ equal or higher than one. Conservatively first-order reactions will be kinetically controlled for $\Phi<0.6$ [46]. Reactions with negative reaction orders, like $\mathrm{CO}$ oxidation over platinum in the $\mathrm{CO}$ self-poisoned regime, are influenced by internal diffusion if $\Phi \geq|n|^{-1}$ [47]. In the present case the transition from the kinetically to the diffusion controlled regime is estimated to occur at about $20 \% \mathrm{CO}$ conversion $(\Phi=0.6)$. This conversion limit is likely overestimated as in the present calculation, the observed reaction rate is related to the entire catalyst layer, which may not be the case. Thus the second phase may here include both the catalytic ignition and light-off processes. In Figure 1, the catalytic ignition occurs at temperatures corresponding to $\mathrm{CO}$ conversions slightly below $20 \%$. Strictly, the ignition temperature is a critical point defined by the Frank-Kamenetskii criterion [48], at which the increase in exothermic heat flux from the reaction exceeds the increase in heat loss flux. This leads to a self-acceleration of the reaction rate $[48,49]$ towards and beyond the light-off temperature (here defined as the temperature for which $50 \%$ reactant conversion is achieved). The catalytic ignition is thus a heat balance and kinetics problem. Finally, the third phase concerns complete conversions, i.e., temperatures well above the lightoff region [50]. Entering this phase means, again, a shift in RDS as here the reaction rate becomes controlled by external (gas phase) diffusion. Analogously, the extinction experiments means the reversed transition from the third to the first phase. In general, the extinction process occurs at considerably lower temperatures than the corresponding ignition process demonstrating a clear ignition-extinction hysteresis. This is partly due to inherent kinetic bistability (see Introduction) and the interplay between reaction kinetics and diffusion phenomena, and partly caused by a heat effect, i.e., exothermic reaction heat generated at the ignition point heats the catalyst so that the inlet gas temperature can be decreased below the temperature required for ignition without influencing the reaction rate significantly $[48,49]$.

From Figure 1 and Table 2, it is clear that both the ignition and extinction processes are shifted towards lower temperatures for the catalyst with heterogeneous $\mathrm{Pt}$ distribution as compared to the homogeneous $\mathrm{Pt} / \mathrm{Al}_{2} \mathrm{O}_{3}$ sample. Also, in the case of $0.1 \% \mathrm{CO}$, the ignition-extinction hysteresis is significantly broader for the heterogeneous sample which essentially is due to a shift of the extinction process from around $145^{\circ} \mathrm{C}$ (homogeneous $\mathrm{Pt} / \mathrm{Al}_{2} \mathrm{O}_{3}$ ) to around $127^{\circ} \mathrm{C}$. These results are in agreement with previous studies $[26,42]$ in which the impact of Pt distribution on the activity for $\mathrm{CO}$ oxidation was discussed in terms of difference in mass transfer, difference in heat transfer, and structure of the active phase. Although difference in mass transfer was pointed out as the most likely cause to the observed effects, the influence of a structure sensitive reaction could not be completely ruled out. Carefully considering the $\mathrm{CO}$ conversion profiles in the second phase, i.e., intermediate conver-
Table 2

Summary of temperatures corresponding to $50 \%$ reactant conversion for the ignition (light-off) and extinction processes over homogeneous and heterogeneous $\mathrm{Pt} / \mathrm{Al}_{2} \mathrm{O}_{3}$ and $\mathrm{Pt} / \mathrm{CeO}_{2}$ catalysts studied by temperature programmed oxidation using heating/cooling rate of $5^{\circ} \mathrm{C} / \mathrm{min}$.

\begin{tabular}{|c|c|c|c|c|c|c|}
\hline \multirow{2}{*}{$\begin{array}{l}\text { Gas composition } \\
\left(\mathrm{N}_{2}-\mathrm{Ar} \text { mixture as carrier }\right)\end{array}$} & \multicolumn{3}{|c|}{ Homogeneous $\mathrm{Pt} / \mathrm{Al}_{2} \mathrm{O}_{3}$} & \multicolumn{2}{|c|}{ Heterogeneous $\mathrm{Pt} / \mathrm{Al}_{2} \mathrm{O}_{3}$} & \multirow{2}{*}{$\frac{\text { Homog }}{\mathrm{T}_{i g} \mathrm{~T}}$} \\
\hline & $\mathrm{T}_{i g n}$ & $\mathrm{~T}_{\text {ext }}$ & $\Delta \mathrm{T}$ & $\mathrm{T}_{i g} \mathrm{~T}_{e x}$ & $\Delta \mathrm{T}$ & \\
\hline $0.1 \% \mathrm{CO}$ & 170 & 145 & 25 & $164 \quad 127$ & 37 & - \\
\hline $1 \% \mathrm{CO}$ & 234 & 176 & 58 & 226169 & 57 & 143 \\
\hline $0.05 \% \mathrm{CH}_{4}$ & - & - & - & - & - & 359 \\
\hline $1 \% \mathrm{CO}+0.05 \% \mathrm{CH}_{4}, \mathrm{CO}:$ & 235 & 180 & 55 & 245185 & 60 & 198 \\
\hline $1 \% \mathrm{CO}+0.05 \% \mathrm{CH}_{4}, \mathrm{CH}_{4}:$ & - & - & - & - & - & 422 \\
\hline $0.1 \% \mathrm{CO}+0.03 \% \mathrm{NO}_{2}$ & 183 & 171 & 12 & 162148 & 14 & 182 \\
\hline $1 \% \mathrm{CO}+0.03 \% \mathrm{NO}_{2}$ & 250 & 209 & 41 & 232192 & 40 & 192 \\
\hline $0.1 \% \mathrm{CO}+5 \% \mathrm{CO}_{2}$ & 176 & 151 & 25 & 166128 & 38 & 162 \\
\hline $1 \% \mathrm{CO}+5 \% \mathrm{CO}_{2}$ & 240 & 179 & 61 & 230170 & 60 & 171 \\
\hline $0.05 \% \mathrm{CH}_{4}+0.03 \% \mathrm{NO}_{2}$ & - & - & - & - & - & 510 \\
\hline
\end{tabular}

sions including the ignition and light-off processes, one can observe that in the case of heterogeneous $\mathrm{Pt} / \mathrm{Al}_{2} \mathrm{O}_{3}$, the increase in $\mathrm{CO}$ conversion through the ignition point is more smooth than for the sample with homogeneous Pt distribution. Also the increase in $\mathrm{CO}$ conversion during light-off is somewhat slower (slope less steep) in the case of heterogeneous $\mathrm{Pt} / \mathrm{Al}_{2} \mathrm{O}_{3}$. As the reaction rate in this phase is controlled by internal diffusion, these observations suggest that for heterogeneous $\mathrm{Pt} / \mathrm{Al}_{2} \mathrm{O}_{3}$, diffusion in the catalyst layer plays a more pronounced role. This can be understood by considering the difference in $\mathrm{Pt}$ distribution. During ignition over the heterogeneous $\mathrm{Pt} / \mathrm{Al}_{2} \mathrm{O}_{3}$ sample, local concentration gradients in the $\mathrm{Pt}$ containing regions of the catalyst layer develop at lower CO conversions as in these regions the $\mathrm{Pt}$ density is higher as compared to the homogeneous $\mathrm{Pt} / \mathrm{Al}_{2} \mathrm{O}_{3}$ catalyst. This results in less $\mathrm{CO}$ self-poisoning and thus ignition occurs at lower temperatures. For the same reasons, i.e., more pronounced concentration gradients, the extinction process is shifted towards lower temperatures for the heterogeneous $\mathrm{Pt} / \mathrm{Al}_{2} \mathrm{O}_{3}$ sample. This is especially clear in the case of $0.1 \% \mathrm{CO}$ because thermal effects through reaction exothermicity are considerably lower than in the case of $1 \% \mathrm{CO}$. Here one may note that complete oxidation of $0.1 \% \mathrm{CO}$ at adiabatic conditions leads to a temperature increase of about $10^{\circ} \mathrm{C}$ while the corresponding oxidation of $1 \% \mathrm{CO}$ increases the temperature further one order of magnitude.

Figure 2 shows the ignition- and extinction experiments for homogeneous and heterogeneous $\mathrm{Pt} / \mathrm{CeO}_{2}$ catalysts, analogous to the experiments with $\mathrm{Pt} / \mathrm{Al}_{2} \mathrm{O}_{3}$ catalysts described above. It is clear that ceria as support material significantly improves the oxidation activity. The light-off temperature for oxidation of $1 \% \mathrm{CO}$ occurs at temperatures almost $100^{\circ} \mathrm{C}$ lower than for the corresponding $\mathrm{Pt} / \mathrm{Al}_{2} \mathrm{O}_{3}$ catalysts. In addition, significant conversion is achieved even at $50^{\circ} \mathrm{C}$, the lowest temperatures studied here, especially in the case of $0.1 \% \mathrm{CO}$ for which no less than about $30 \%$ and $40 \%$ conversion is achieved for, respectively, the heterogeneous and homogeneous $\mathrm{Pt} / \mathrm{CeO}_{2}$ catalyst. Al- 
though the conversion of $\mathrm{CO}$ below light-off is higher in the case of homogeneous $\mathrm{Pt} / \mathrm{CeO}_{2}$, the heterogeneous $\mathrm{Pt} / \mathrm{CeO}_{2}$ catalyst reaches light-off at about $20^{\circ} \mathrm{C}$ lower temperature. Interestingly, the width of the ignition-extinction hysteresis is similar and the conversion of CO passes through a minimum during the ignition- and extinction experiments for both catalysts.

To efficiently utilise noble metals, ceria can be used as support to achieve high precious metal dispersion, thereby achieving high activity per mass of metal [36,37]. In this study, such dispersion effects are expected to be minor as the apparent platinum dispersion for the present catalysts is deliberately similar. We recall that the differences in $\mathrm{CO}$ uptake of the ceria catalysts may be due to the inherent properties of the $\mathrm{Pt} / \mathrm{CeO}_{2}$ system and thus not solely indicative of varying $\mathrm{Pt}$ dispersions [43]. In ceria, Ce is well known to have the ability to readily change oxidation state $\left(\mathrm{Ce}^{4+} \leftrightarrow \mathrm{Ce}^{3+}\right)$ thereby provide a function as an oxygen storage- and release material [51]. Moreover ceria can facilitate transport of oxygen mainly through surface diffusion but also via bulk diffusion at sufficiently high temperatures (above $400^{\circ} \mathrm{C}[52]$ ). Thus, in the case of $\mathrm{CO}$ oxidation over $\mathrm{Pt} / \mathrm{CeO}_{2}$ catalysts, ceria has been suggested to provide an additional channel for transport of oxygen to the Pt crystallites through reversed spill-over, i.e., oxygen diffusion from the ceria support to the Pt crystallites [38,39], thereby supress the effect of CO self-poisoning. This can partly explain the present results. However, the ignitionand extinction processes observed here occur well below $150^{\circ} \mathrm{C}$. At these temperatures, transport of oxygen in the ceria bulk is negligible and surface diffusion is likely minor [52] which suggests that also other mechanisms may be important. For example, in contrast to the $\mathrm{Pt} / \mathrm{Al}_{2} \mathrm{O}_{3}$ catalyst, platinum supported on ceria may exhibit SMSI [16] and connected to this, ceria as support may result in electronic promotion of the Pt crystallites or exclusive active sites at the platinum-ceria boundary [40,53] favoring the $\mathrm{CO}$ oxidation. The latter may favor processes like CO spill-over, $\mathrm{O}_{2}$ dissociation or give rise to more oxidised $\mathrm{Pt}$ species at the boundary, through reversed oxygen spill-over [54], for which the adsorption of CO is weak. In all these cases the boundary sites are expected to be less sensitive towards $\mathrm{CO}$ poisoning. We mention that the oxidation of $\mathrm{CO}$ on bare ceria has been reported to be minor at these temperatures [55]. The further improvement of the $\mathrm{CO}$ oxidation activity for heterogeneous $\mathrm{Pt} / \mathrm{CeO}_{2}$ is then likely due to the effect of heterogeneous $\mathrm{Pt}$ distribution analogous to the case of $\mathrm{Pt} / \mathrm{Al}_{2} \mathrm{O}_{3}$ discussed above. The peculiar minimum in $\mathrm{CO}$ conversion is more difficult to explain. For example, CO adsorption/desorption phenomena that lead to a net accumulation/release may cause an apparent minimum in $\mathrm{CO}$ conversion. This explanation, however, seems less likely. The detailed analysis of the carbon balance $\left(\mathrm{CO}+\mathrm{CO}_{2}\right)$ reveals negligible carbon accumulation at low temperatures or, in other words, the amounts of produced $\mathrm{CO}_{2}$ corresponds well with the consumed amounts of CO. Considering this, we can only speculate on the un- derlying phenomena. For example during the change of the temperature the mobility of surface species is also changed possibly leading to a rearrangement of adsorbed $\mathrm{CO}$ from ceria to platinum sites. This can result in a temporary low activity in the pre-ignition regime.

The influence of $\mathrm{NO}_{2}$ and $\mathrm{CO}_{2}$ on the ignition- and extinction processes was studied as well. In Figure 3 and 4, the results from $\mathrm{CO}$ oxidation in the presence of $0.03 \% \mathrm{NO}_{2}$ for, respectively, the $\mathrm{Pt} / \mathrm{Al}_{2} \mathrm{O}_{3}$ and $\mathrm{Pt} / \mathrm{CeO}_{2}$ catalysts, are shown. The corresponding results for $\mathrm{CO}_{2}$ addition are only shown in Table 2 . Addition of $\mathrm{NO}_{2}$ clearly shifts the ignition- and extinction processes towards higher temperatures for all catalysts. In the case of $1 \% \mathrm{CO}$, the light-off temperature is shifted about $20^{\circ} \mathrm{C}$ for $\mathrm{Pt} / \mathrm{Al}_{2} \mathrm{O}_{3}$ and $50^{\circ} \mathrm{C}$ for $\mathrm{Pt} / \mathrm{CeO}_{2}$. The extinction process in the respective case is shifted even more leading to narrower ignition-extinction hysteresis. The results for $0.1 \% \mathrm{CO}$ is similar, however, for the $\mathrm{Pt} / \mathrm{Al}_{2} \mathrm{O}_{3}$ catalysts, $\mathrm{NO}_{2}$ addition significantly increases the $\mathrm{CO}$ conversion below the ignition temperature. Addition of $\mathrm{CO}_{2}$ has a minor influence on the $\mathrm{CO}$ oxidation over $\mathrm{Pt} / \mathrm{Al}_{2} \mathrm{O}_{3}$ while for the $\mathrm{Pt} / \mathrm{CeO}_{2}$ catalyst the ignitionand extinction processes are shifted about $30^{\circ} \mathrm{C}$ towards higher temperatures.

At the temperatures studied here, a less active oxide-like platinum phase can be formed during $\mathrm{CO}$ oxidation over $\mathrm{Pt} / \mathrm{Al}_{2} \mathrm{O}_{3}$ [14], especially in the presence of $\mathrm{NO}_{2}$. Experiments with $\mathrm{NO}_{2}$ pre-treated $\mathrm{Pt} / \mathrm{Al}_{2} \mathrm{O}_{3}$ subsequently exposed to CO support this [14]. Although the detailed mechanism/characteristics of the oxide formation is not clear, models based on a nucleation process followed by growth of oxide islands have been suggested [21]. In the case of $\mathrm{Pt} / \mathrm{Al}_{2} \mathrm{O}_{3}$, the observed shift of the ignition- and extinction processes towards higher temperatures can thus be due to formation of a platinum oxide phase slightly after the ignition point where the CO coverage is low. The increased $\mathrm{CO}$ conversion before light-off that is observed only for the lowest level of $\mathrm{CO}(0.1 \%)$ where the $\mathrm{CO}$ poisoning is less severe, is likely due to dissociation of $\mathrm{NO}_{2}$ on the (few) available free sites not accessible for $\mathrm{O}_{2}$ dissociation. An alternative explanation may involve an Eley-Rideal reaction between gaseous $\mathrm{NO}_{2}$ and chemisorbed $\mathrm{CO}$. However, if this would be the case, the same effect should most likely have been observed also for $1 \% \mathrm{CO}$, provided the amount of $\mathrm{NO}_{2}$ is sufficient. For $\mathrm{Pt} / \mathrm{CeO}_{2}$ the decreased activity is likely due to the formation of nitrates and carbonates on the ceria surface that hinder surface diffusion or block active sites on the platinum-ceria boundary.

\subsection{Oxidation of $\mathrm{CH}_{4}$ and $\mathrm{CO}+\mathrm{CH}_{4}$ mixture}

Figure 5 shows the results from TPO of $0.05 \% \mathrm{CH}_{4}$ over homogeneous (top panel) and heterogeneous (middle panel) $\mathrm{Pt} / \mathrm{Al}_{2} \mathrm{O}_{3}$, and homogeneous and heterogeneous $\mathrm{Pt} / \mathrm{CeO}_{2}$ (bottom panel) during heating-cooling ramps. For the $\mathrm{Pt} / \mathrm{Al}_{2} \mathrm{O}_{3}$ catalysts, the conversion of $\mathrm{CH}_{4}$ reaches only $10-20 \%$ at the top temperature $\left(550^{\circ} \mathrm{C}\right)$ studied here. 
Contrarily, the $\mathrm{Pt} / \mathrm{CeO}_{2}$ catalysts are rather active showing a light-off temperature of 359 and $385^{\circ} \mathrm{C}$ for, respectively, the homogeneous and heterogeneous $\mathrm{Pt} / \mathrm{CeO}_{2}$ catalyst. In contrast to the $\mathrm{CO}$ oxidation experiments discussed above, the homogeneous catalyst exhibit the lower light-off temperature and no ignition-extinction hysteresis can be observed.

Previous studies have shown that the oxidation of methane over alumina supported platinum is sensitive towards the surface $\mathrm{O} / \mathrm{Pt}$ ratio $[28,29]$. The term $\mathrm{O} / \mathrm{Pt}$ ratio was introduced to account for oxygen in any type of platinum-oxygen species as the IUPAC definitions provide no clear distinction between adsorbed oxygen and platinum oxides [56]. Since in this study, excess oxygen was used in all experiments, the surface $\mathrm{O} / \mathrm{Pt}$ ratio is expected to be high and thus this is the main explanation to the low methane conversion. For $\mathrm{Pt} / \mathrm{CeO}_{2}$ the situation is obviously different. The $\mathrm{O} / \mathrm{Pt}$ ratio is expected to be high also in this case, possibly even higher due to the influence of the ceria support on the Pt crystallites. The oxidation of methane over bare ceria is minor even though dissociation of methane may occur [41]. One may consider methane dissociation on ceria with subsequent diffusion of dissociation products to the $\mathrm{Pt}$ crystallites where oxidation occurs to explain the results. However, we find this scenario unlikely as methane dissociation probably leads to the formation of various, relatively stable, carbonate- and hydroxyl species on the support. Moreover, the effective oxygen storage function that may drain oxygen from the $\mathrm{Pt}$ crystallites through spill-over and further diffusion on/into ceria thereby lowering a detrimentally high surface $\mathrm{O} / \mathrm{Pt}$ ratio, as suggested for transient studies [40], can hardly explain the present results as continuous oxygen excess was used. Instead we propose, in line with the discussion above, that the $\mathrm{Pt} / \mathrm{CeO}_{2}$ system may provide highly active sites located at the platinum-ceria boundary, that can dissociate methane also under oxygen excess conditions. The reason for the slightly higher activity for the homogeneous catalyst can be a result of the difference in the local $\mathrm{Pt}$ loading, i.e., amount of Pt per unit area of support.

We consider now the oxidation of the $\mathrm{CO}+\mathrm{CH}_{4}$ mixture. The results for simultaneous oxidation of $1 \% \mathrm{CO}$ and $0.05 \% \mathrm{CH}_{4}$ over $\mathrm{Pt} / \mathrm{CeO}_{2}$ catalysts are shown in Fig 6 . As the ignition- and extinction processes for the two reactions occur in different temperature regions it is tempting to simply treat these as two independent reactions. This is, however, not the case. The CO conversion profiles are shifted to higher temperatures and a reverse ignition-extinction hysteresis (i.e. extinction at higher temperatures than ignition), is observed for the methane oxidation. The oxidation of methane alone shows no such hysteresis, cf. Fig 5. The decreased activity for $\mathrm{CO}$ oxidation can be due to the blocking of a significant number of the Pt sites by methane dissociation products that cannot be oxidised within this temperature region, so that the CO self-poisoning that eventually occurs during extinction is facilitated. The reversed hysteresis in methane conversion likely originates from reduction- and oxidation of $\mathrm{Pt}$ sites. We recall that the extinction experiment was carried out before the ignition experiment. At the start of the extinction experiment, the surface $\mathrm{O} / \mathrm{Pt}$ ratio is high and the ceria is in a high oxidation state. The sites mainly responsible for the activity are likely those located at the platinum-ceria boundary as discussed above. During extinction of the oxidation reactions the Pt surface is reduced. As methane dissociation strongly depends on the coverage of other species, the extinction of the methane oxidation likely results in partial reduction of the $\mathrm{Pt}$ surface by methane dissociation products. The extinction of the $\mathrm{CO}$ oxidation reaction then corresponds to a more complete reduction of the $\mathrm{Pt}$ surface. The reduced state, which is more active for methane oxidation, is then the initial condition for the ignition experiment. Consequently, an improved conversion of methane below light-off and lower light-off temperature is seen which in turn results in a reverse ignition-extinction hysteresis. The maximum conversion in the ignition- and extinction experiments occurs at about the same temperature, i.e., the kinetics for the oxidation of the $\mathrm{Pt}$ crystallites is sufficiently fast to reach the state where again the sites at the platinum-ceria boundary are mainly responsible for the methane conversion.

\section{Concluding remarks}

The oxidation of $\mathrm{CO}, \mathrm{CH}_{4}$, and $\mathrm{CO}+\mathrm{CH}_{4}$ mixture in excess oxygen over $\mathrm{Pt} / \mathrm{Al}_{2} \mathrm{O}_{3}$ and $\mathrm{Pt} / \mathrm{CeO}_{2}$ catalysts with the platinum phase distributed either homogeneously or heterogeneously in the support material have been studied by temperature programmed experiments. The results show that the catalytic activity follows the order: $\mathrm{Pt} / \mathrm{CeO}_{2}$ (heterogeneous) $>\mathrm{Pt} / \mathrm{CeO}_{2} \quad$ (homogeneous) $>\mathrm{Pt} / \mathrm{Al}_{2} \mathrm{O}_{3}$ (heterogeneous) $>\mathrm{Pt} / \mathrm{Al}_{2} \mathrm{O}_{3}$ (homogeneous) as indicated by lower ignition- and/or extinction temperatures. Also, the influence of $\mathrm{NO}_{2}$ on the oxidation of $\mathrm{CO}$ and $\mathrm{CH}_{4}$ as well as the influence of $\mathrm{CO}_{2}$ on $\mathrm{CO}$ oxidation were studied. For $\mathrm{Pt} / \mathrm{Al}_{2} \mathrm{O}_{3}, \mathrm{NO}_{2}$ increases the activity for $\mathrm{CO}$ oxidation in the pre-ignition regime although the light-off temperature is shifted towards higher temperatures. For methane oxidation over $\mathrm{Pt} / \mathrm{Al}_{2} \mathrm{O}_{3}$ the activity generally increases when $\mathrm{NO}_{2}$ is added. The addition of $\mathrm{CO}_{2}$ has minor influence on the activity for $\mathrm{CO}$ oxidation. In the case of $\mathrm{Pt} / \mathrm{CeO}_{2}$, the activity for oxidation of $\mathrm{CO}$ and $\mathrm{CH}_{4}$ decreases dramatically in the presence of $\mathrm{NO}_{2}$. The addition of $\mathrm{CO}_{2}$ decreases the activity for $\mathrm{CO}$ oxidation. For the simultaneous oxidation of $\mathrm{CO}$ and $\mathrm{CH}_{4}$, a reverse hysteresis for methane oxidation is observed, i.e., the extinction process occurs at higher temperature than the corresponding ignition process.

The improved activity for CO oxidation over samples with heterogeneous $\mathrm{Pt}$ distribution is likely due to less tendency towards CO self-poisoning through the development of steeper concentration gradients in the Pt containing regions of the porous support material, i.e., the effect of het- 
erogeneous Pt distribution is related mainly to mass transport phenomena. This is further supported by the fact that mehane oxidation is not significantly influenced by the heterogeneous $\mathrm{Pt}$ distribution. The considerable increase of activity for both reactions over ceria supported $\mathrm{Pt}$ is here assigned to highly active sites at the platinum-ceria boundary but also, to some extent, the oxygen storage- and release function and dynamics of the transport of oxygen in the $\mathrm{Pt} / \mathrm{CeO}_{2}$ system.

\section{Acknowledgments}

This work has been performed within PAGODE program Proj. no. 2005-3592 and the Competence Centre for Catalysis, which is hosted by Chalmers University of Technology and financially supported by the Swedish Energy Agency and the member companies AB Volvo, Volvo Car Corporation, Scania CV AB, Saab Automobile Powertrain AB, Haldor Topsøe A/S, and ECAPS AB.

\section{References}

[1] P. Gélin, M. Primet, Appl. Catal. B: Environ. 39 (2002) 1-37.

[2] R. M. Heck and R. J. Farrauto, Appl. Catal. A: General 221 (2001) 443-57.

[3] H. S. Gandhi, G. W. Graham and R. W. McCabe, J. Catal. 216 (2003) 433-42.

[4] G. Lenaers, Sci. Total. Environ. 190 (1996) 139-47.

[5] M. Skoglundh, E. Fridell, Top. Catal. 28(1-4) (2004) 79-87.

[6] S. A. Lewis, J. M. E. Storey, B. Bunting, J. P. Szybist, SAE technical paper series 2005-01-3737.

[7] S. V. Bohac, M. Han, T. J. Jacobs, A. J. López, D. N. Assanis, SAE technical paper series 2005-01-3737.

[8] J. Wei, Adv. Catal. 24 (1975) 57-129.

[9] G. Ertl, T. Engel, Adv. Catal. 28 (1979) 1-77.

[10] M. Bär, Ch. Zülicke, M. Eiswirth and G. Ertl, J. Chem. Phys. 96(11) (1992) 8595-8604.

[11] V. P. Zhdanov and B. Kasemo, Surf. Sci. Rep. 20 (1994) 111-89.

[12] S. Salomons, R. E. Hayes, M. Votsmeier, A. Drochner, H. Vogel, S. Malmberg and J. Gieshoff, Appl. Catal. B: Environ. 70 (2007) 305-13.

[13] P.-A. Carlsson, M. Skoglundh, E. Fridell, E. Jobson and B. Andersson, Catal. Today. 73 (2002) 307-13.

[14] P.-A. Carlsson, M. Skoghlundh, P. Thormählen and B. Andersson, Top. Catal. 30/31 (2004) 375-81.

[15] P.-A. Carlsson, V. P. Zhdanov and M. Skoghlundh, Phys. Chem. Chem. Phys. 8 (2006) 2703-6.

[16] S. Bernal, J. J. Calvino, M. A. Cauqui, J. M. Gatica, C. Larese, J. A. Pérez Omil and J. M. Pintado, Catal. Today 50 (1999) 175-206.

[17] L. F. Liotta, A. Longo, A. Macaluso, A. Martorana, G. Pantaleo, A. M. Venezia and G. Deganello, Appl. Catal. B: Environ. 48 (2004) 133-49.

[18] J. Libuda, H.-J. Freund, Surf. Sci. rep. 57 (2005) 157-298.

[19] V. P. Zhdanov and B. Kasemo, J. Catal. 170 (1997) 377-89.

[20] P.-A. Carlsson, L- Österlund, P. Thormählen, A. Palmqvist, E. Fridell, M. Skoglundh, J. Catal. 226 (2004) 422-34.

[21] P.-A. Carlsson, V. P. Zhdanov, B. Kasemo, Appl. Surf. Sci. 239 (2005) 424-31.

[22] R. Burch and M. J. Hayes, J. Mol. Catal. A: Chemical, 100 (1995) 13-33.

[23] R. Burch, D. J. Crittle, M. J. Hayes, Catal. Today. 47 (1999) 229-34.
[24] S. Oh, P. J. Mitchell and R. M. Siewert, J. Catal. 132 (1991) 287-310.

[25] P.-A. Carlsson, S. Mollner, K. Arnby, M. Skoglundh, Chem. Sci. Eng. 59 (2004) 4313-23.

[26] K. Arnby, J. Assiks, P.-A. Carlsson, A. Palmqvist, M. Skoglundh, J. Catal. 233 (2005) 176-85.

[27] P.-A. Carlsson, E. Fridell, M. Skoglundh, Catal. Lett. 115(1-2) (2007) 1-7.

[28] E. Becker, P.-A. Carlsson, H. Grönbeck, M. Skoglundh, J. Catal. 252 (2007) 11-17.

[29] E. Becker, P.-A. Carlsson, L. Kylhammar, M. Newton and M. Skoglundh, J. Phys. Chem. C (2010).

[30] P.-A. Carlsson, M. Nordström and M. Skoglundh, Top. Catal. 52 (2009) 1962-66.

[31] V. P. Zhdanov, P.-A. Carlsson, B. Kasemo, J. Chem. Phys. 126 (2007) 234705.

[32] H. C. Yao and Y. Y.-F. Yao, J. Catal. 86 (1984) 254-65.

[33] E. C. Sue, C.N. Montreuil and W. G. Rothchild, Appl. Catal. 17 (1985) $75-86$

[34] J. S. Rieck and A. T. Bell, J. Catal. 99 (1986) 278-92.

[35] G. Kim, Ind. Eng. Chem. Prod. Res. Dev. 21 (1982) 267-74.

[36] H. S. Gandhi and M. Shelef,, "Catalysis and Automotive Pollution Control", A. Crucq and A. Frennet (Editors), 1987, pp. 199-214.

[37] H.C. Yao, Appl. Surf. Sci. 19 (1984) 398-406.

[38] S. Johansson, L. Österlund, B. Kasemo, J. Catal. 201 (2001) $275-85$.

[39] E. Becker, P. Thormählen, T. Maunula, A. Suopanki and M. Skoglundh, Top. Catal. 42/43 (2007) 421-24.

[40] E. Becker, P.-A. Carlsson and M. Skoglundh, Top. Catal. 52 (2009) 1957-61.

[41] E. Odier, Y. Schuurman and C. Mirodatos, Catal. Today 127 (2007) 230-37.

[42] K. Arnby, A. Törncrona, B. Andersson, M. Skoglundh, J. Catal. 221 (2004) 252-61.

[43] S. Bernal, J. J. Calvino, J. M. Gatica, C. L. Cartes and J. M. Pintado, "Catalysis by ceria and related materials". A. Trovarelli (Editor), 2002, pp. 85-167.

[44] P. Ericsson, M. Holmström, A. Amberntsson-Carlsson C. Ohlson, M. Skoglundh, B. Andersson and P.-A. Carlsson, SAE technical paper series 2007-01-1746.

[45] P. B. Weisz and C. D. Prater, Adv. Catal. 6 (1954) 143-96.

[46] P. B. Weisz, Z. Physik. Chem., Neue Folge, 11 (1957) 1.

[47] D. E. Mears. Ind. Eng. Chem. Process. Des. Develop. 10(4) (1971) 541- 47.

[48] D. A. Frank-Kamenetskii, "Diffusion and heat transfer in chemical kinetics", Plenum press, New York, 1969, p. 487.

[49] A. Schwartz, L. L. Holbrook and H. Wise, J. Catal. 21 (1971) 199-207.

[50] S. Y. Joshi, M. P. Harold and V. Balakotaiah, Chem. Eng. Sci. 65 (2010) 1729-47.

[51] A. Trovarelli, Catal. Rev. Sci. Eng. 38 (1996) 439-520.

[52] D. Martin and D. Duprez, J. Phys. Chem. 100 (1996) 9429-38.

[53] P. Bazin, O. Sour, J. C. Lavalley, M- Daturi and G. Blanchard, Phys. Chem. Chem. Phys. 7 (2005) 187-94.

[54] Y. Lykhach, T. Staudt, M. P. A. Lorenz, R. Streber, A. Bayer, H.-P. Steinrück and J. Libuda, Chem. Phys. Chem. 11 (2010) 1496-1504.

[55] E. Aneggi, J. Llorca, M. Boaro and A. Trovarelli, J. Catal. 234 (2005) 88-95.

[56] R. Burwell, Adv. Catal. 26 (1977) 351-93. 


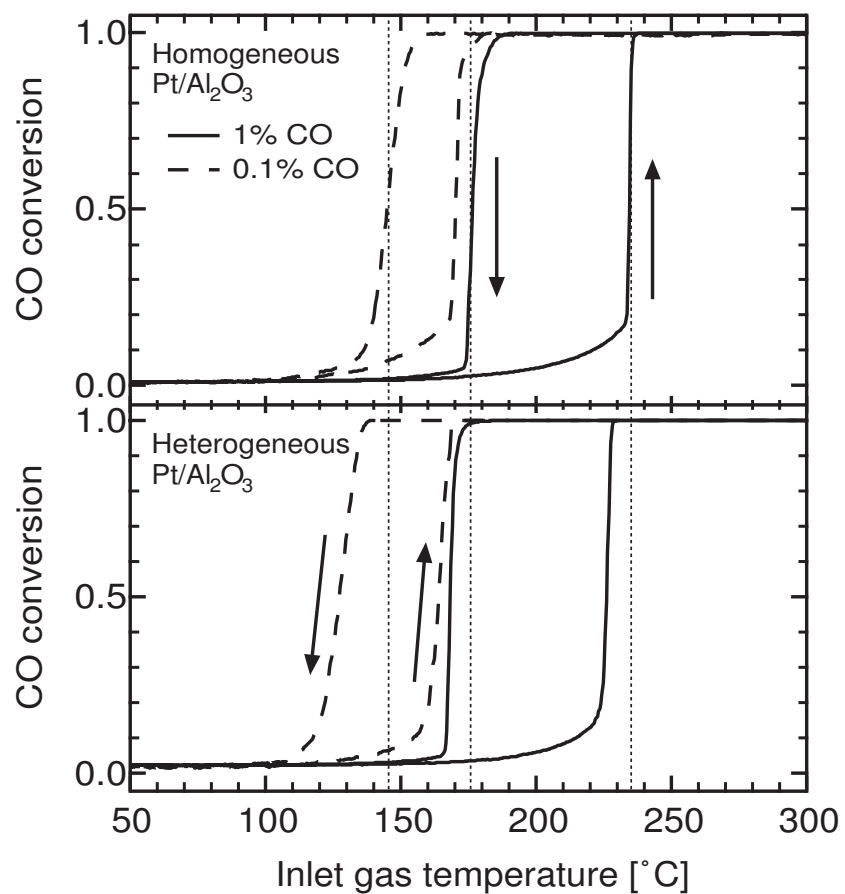

Fig. 1. Temperature programmed oxidation of 0.1 and $1 \%$ CO with $9 \% \mathrm{O}_{2}$ over homogeneous (top panel) and heterogeneous (bottom panel) $\mathrm{Pt} / \mathrm{Al}_{2} \mathrm{O}_{2}$ monolith catalysts using heating/cooling rates of $5^{\circ} \mathrm{C} / \mathrm{min}$.

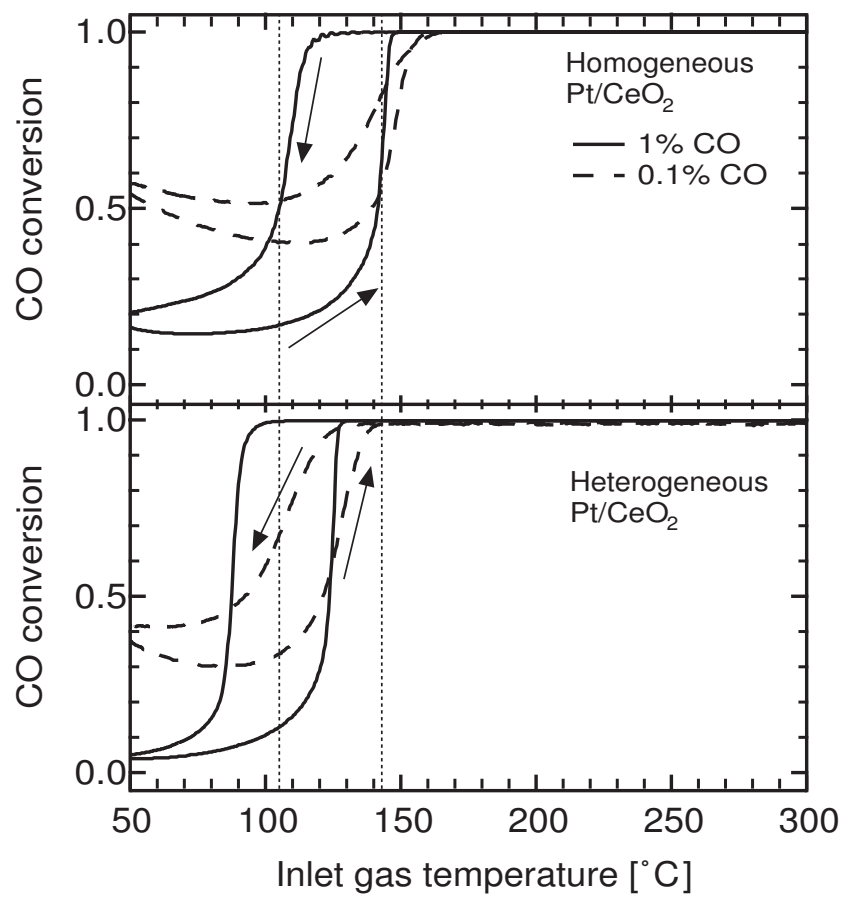

Fig. 2. Temperature programmed oxidation of 0.1 and $1 \% \mathrm{CO}$ with $9 \% \mathrm{O}_{2}$ over homogeneous (top panel) and heterogeneous (bottom panel) $\mathrm{Pt} / \mathrm{CeO}_{2}$ monolith catalysts using heating/cooling rates of $5^{\circ} \mathrm{C} / \mathrm{min}$.

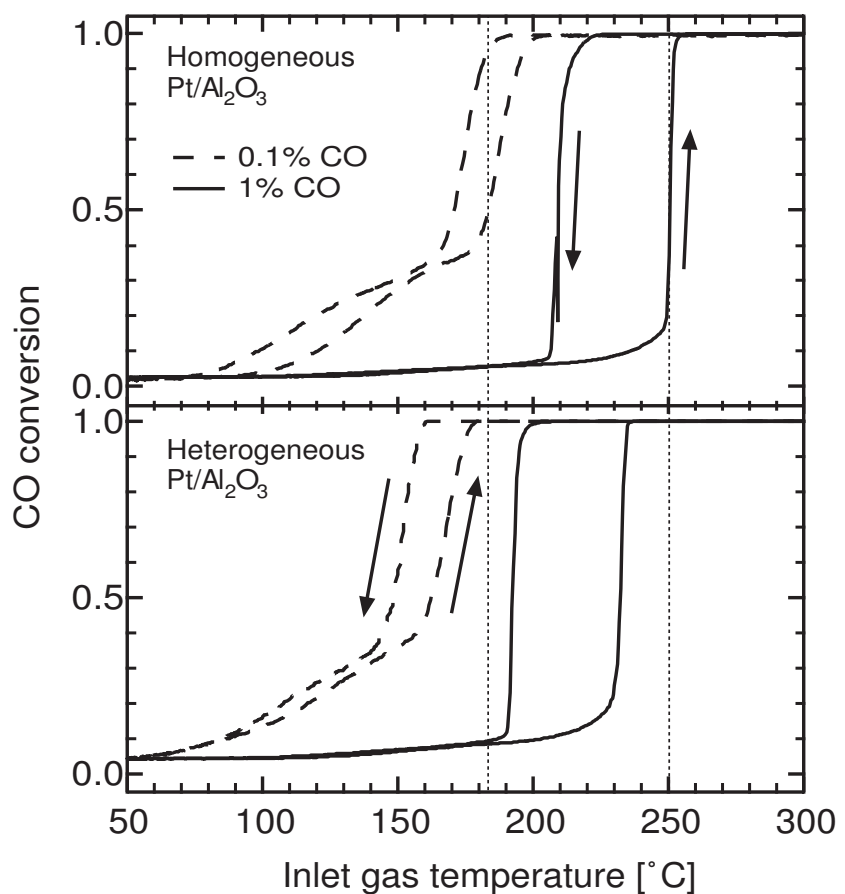

Fig. 3. Temperature programmed oxidation of 0.1 and $1 \% \mathrm{CO}$ with $9 \% \mathrm{O}_{2}$ in the presence of $0.03 \% \mathrm{NO}_{2}$ over homogeneous (top panel) and heterogeneous (bottom panel) $\mathrm{Pt} / \mathrm{Al}_{2} \mathrm{O}_{2}$ monolith catalysts using heating/cooling rates of $5^{\circ} \mathrm{C} / \mathrm{min}$.

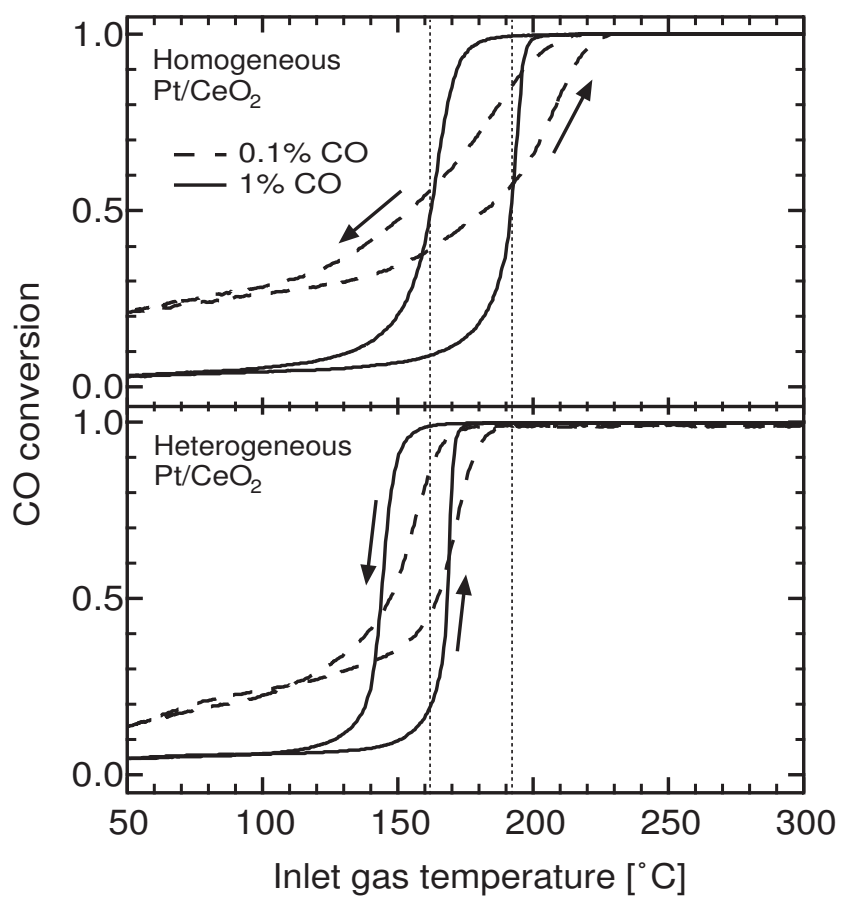

Fig. 4. Temperature programmed oxidation of 0.1 and $1 \% \mathrm{CO}$ with $9 \% \mathrm{O}_{2}$ in the presence of $0.03 \% \mathrm{NO}_{2}$ over homogeneous (top panel) and heterogeneous (bottom panel) $\mathrm{Pt} / \mathrm{CeO}_{2}$ monolith catalysts using heating/cooling rates of $5^{\circ} \mathrm{C} / \mathrm{min}$. 


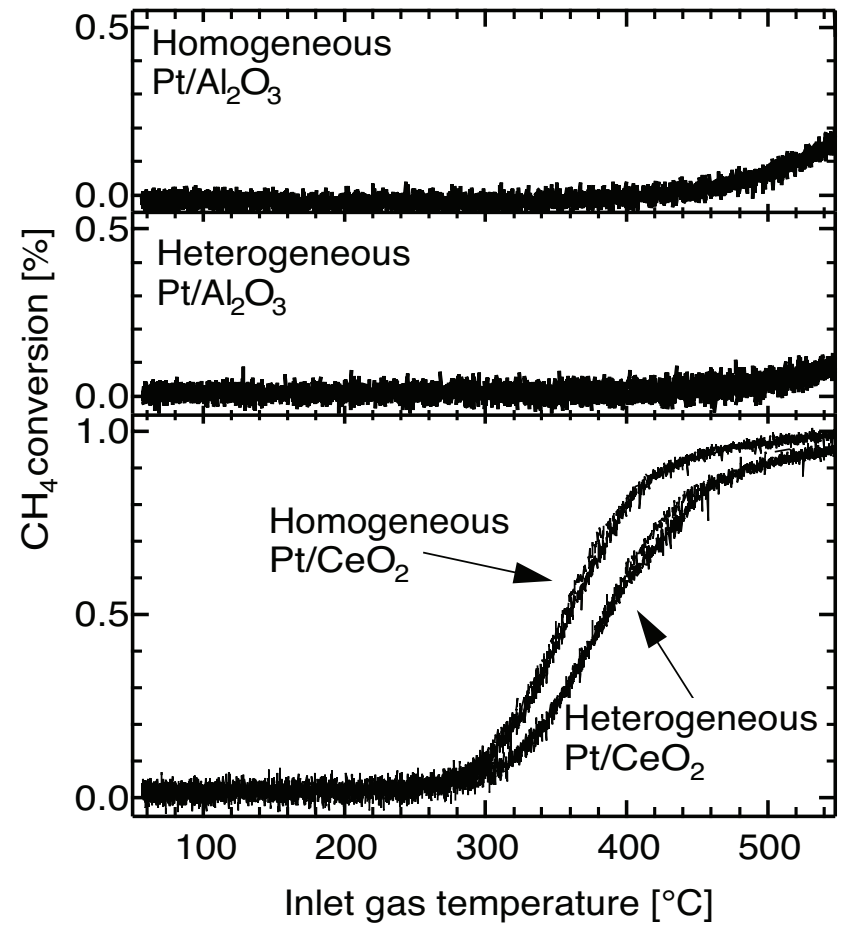

Fig. 5. Ignition and extinction of oxidation of $\mathrm{CH}_{4}$ over homogeneous and heterogeneous $\mathrm{Pt} / \mathrm{Al}_{2} \mathrm{O}_{2}$ monolith catalysts (top and middle panel respectively) and the corresponding $\mathrm{Pt} / \mathrm{CeO}_{2}$ catalysts (bottom panel).

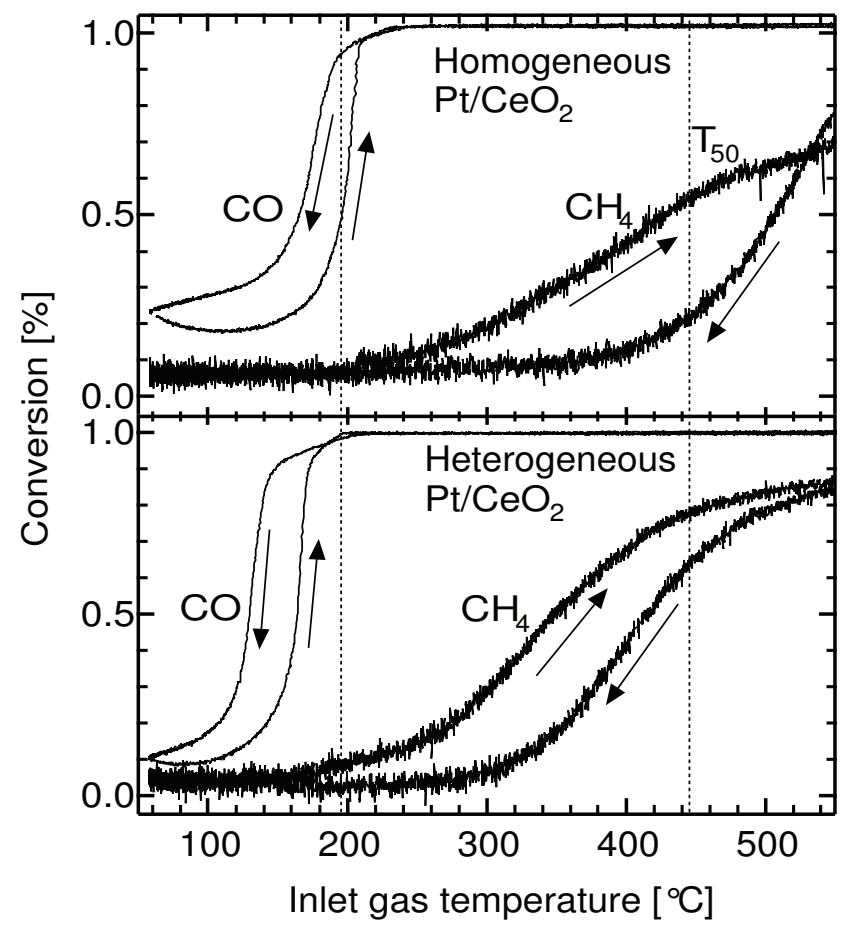

Fig. 6. Ignition and extinction of oxidation of $\mathrm{CO}+\mathrm{CH}_{4}$ over homogeneous (top panel) and heterogeneous (bottom panel) $\mathrm{Pt} / \mathrm{CeO}_{2}$ monolith catalysts. 